\title{
Comparative Experimental Analysis of Temperature Distribution in Mini Size Permeable and Non-Permeable Varying Salt Density Solar Pond
}

\author{
Periyasamy Rangaraju ${ }^{1 *}$, Santhia Sivakumar ${ }^{2}$ \\ ${ }^{1}$ Karpagam College of Engineering, Othakalmandapam, Coimbatore, Tamil Nadu 641032, India \\ ${ }^{2}$ Government College of Engineering Salem, Salem, Tamil Nadu 636011, India
}

Corresponding Author Email: rperiyasamy13@gmail.com

https://doi.org/10.18280/ijht.390218

Received: 2 July 2020

Accepted: 26 December 2020

\section{Keywords:}

temperature distribution, varying salt density, conventional solar pond, permeable solar pond, thermal energy storage

\begin{abstract}
Varying salt density solar pond is a method that is best suited to absorb and store solar energy. This examination includes the test enhancement of the permeable and nonpermeable sunlight-based ponds dependent on its exhibition in different conditions. This experiment was done in Salem, Tamil Nadu, India. This particular topographical area has a high level of solar radiation and is a tropical district. Readings for a period of 30 days were taken; the temperature circulation, a measure of heat energy stored and concentration of salt density was assessed. For examination, two comparable solar ponds of volume 0.02 $\mathrm{m}^{3}$ and a height of $0.32 \mathrm{~m}$ was built. Black granite pieces, broken glass pieces, and welding spatter were used as a permeable medium in the lower convective zone (LCZ) in one of the two solar ponds. The temperatures of the permeable solar pond and non-permeable solar pond reached the highest values of $42.3^{\circ} \mathrm{C}$ and $40.6^{\circ} \mathrm{C}$ respectively. The solar pond with a permeable medium demonstrated an increase of $4.18 \%$ in temperature. The difference in amounts of stored thermal energy is $4.54 \mathrm{~kJ}$. From the obtained parameters, the optimization is done and the permeable medium solar pond is found to store more amount of heat energy than the non- permeable solar pond. For the optimization of the mixed medium, criterion parameter $\beta_{\text {elk }}$ has been acquired in the solar pond.
\end{abstract}

\section{INTRODUCTION}

Ecological concerns have prompted the utilization of energy from the sun, which is increasingly plenteous and appropriate. It can utilize and store all the while during the daytime. Sunlight based lakes are one of the notable warmth stockpiling frameworks, which aggregate warm vitality utilizing sun oriented radiation. A solar pond is a very large, controllable body that contains water that can absorb and store solar energy. They never use tracking systems such as mirrors, nor do they concentrate the solar radiation as in many other sun's energy technologies. There are two types of convective solar ponds one is the shallow solar pond and the deep saltless pond. Salinity gradient solar pond, membrane solar pond, and polymer gel layers solar pond are the major types of nonconvective solar ponds.

The movement of heat energy can be characterized as the development or move of thermal energy starting with one thing then onto the next thing which at various temperatures. The heat is moved typically moved from an object of very high temperature to an object of very low temperature. The transfer of heat for the most part delivers a few changes in the inner vitality of both the frameworks which are associated with heat move. This is as indicated by the first law of thermodynamics.

Basically, there are three kinds of heat transfer namely conduction, convection, and radiation.

Conduction is one of the methods of heat transfer it is of by implies that the heat transfer happens because of the atomic commotion inside material with no movement of the material fully. For instance, on the off chance that one finish of a metal pole is at a higher temperature, at that point. the heat transfer will be moved to the opposite finish of the pole which is colder end because the particles move with higher speed and will crash into the slower ones with a complete exchange of energy to the slower ones.

Convection is one the mode of heat transfer occurs by the movement of any fluid (a liquid or a gas) between the objects or places of different temperature. It also can be termed as the bulk movement of liquid due to the density differences in the liquid. Generally, the warm air is less thick than the cold air, thus within the sight of a temperature angle convection flows can shape. Convection is of two types namely natural convection and forced convection. Natural convection is produced in the fluid when the currents are produced by the density differences which are temperature-derived. Forced convection is termed when the external factor such as a pump or fan induces convection currents. The rate of convection is directly proportional to the movement of the fluid.

Radiation is characterized as the exchange of heat from a body in high temperature to a body in a lower temperature, when bodies are not in direct physical contact with one another or when they are isolated in space, is called heat radiation.

Varying salt density solar ponds are one of the various sorts of solar ponds, which can be shaped by applying various kinds of salts. Varying salt density comprises of three layers. The main zone is the surface layer with the least salt and thickness, which alludes to the upper convective zone (UCZ). The UCZ is in atmospheric temperature and is the topmost layer in the solar ponds. The density of salt in this layer is very less when compared to other layers. At that point the subsequent zone, 
which is the center layer, and alludes to the non-convective zone (NCZ). Here, saturation increases by the depth and thickness being greater than UCZ. At last, the lowest layer alludes to the lower convective zone (LCZ), which is in a saturated condition. The Lower Convective Zone is present at the bottom of the solar pond. It has the most noteworthy saltiness among the three layers in the solar pond. The heat energy is stored in this layer. NCZ acts as thermal insulation for the bottom layer and aids in the prevention of heat loss. Despite the entrance of solar radiation into the profundity, it can't escape from the zone. Assari et al. [1], examined tentatively the exhibition of mixed medium in the lower convection zone of laboratory-scale solar pond. An expansion of $5.6 \%$ in temperature appears in the blended medium sun oriented lake. What's more, the variety of the most extreme temperature of the blended medium lake was not exactly the customary LCZ sun oriented lake. Progressively warm dependability and lower temperature drop are gotten by utilizing a blended medium in the LCZ. Additionally, the utilization of blended medium demonstrated higher warm obstruction and more stockpiling limit concerning the pond.

Hill and Carr [2], researched the straight insecurity of a sunlight-based lake containing permeable material in the lower convective zone (LCZ). It is discovered that, when all is said in done, sun oriented lakes that contain permeable material are progressively steady for truly sensible qualities.

Shi et al. [3] studied the impacts of permeable media on warm and salt dispersion of the solar ponds. It is shown that the heat insulation effect is enhanced by the expansion of permeable media to the base of a sun-based lake.

Silva and Almanza [4] researched the physical, substance, and water-powered properties of various soils tried mostly as compacted dirt liners. Because of the wide varieties in the materials utilized for sun-powered lake lining, studies ought to be routed to portray they're drawn-out exhibition within the sight of sweltering saline solutions.

Velmurugan et al. [5], tried the exhibition of balance type single bowl sunlight based still when it is altered with dark elastic, wipe, and sand, and the ventured sun oriented despite everything was changed with balance, rock, and wipe. The most extreme profitability of $100 \%$ was acquired when the blade type ventured sun based was incorporated with rock and wipe.

Wang et al. [6], studied the temperature improvement of including coal soot at the base of SGSP has been tentatively and hypothetically. The outcomes show that contrasted with the conventional base treatment the expansion of coal soot at the base of SGSP prompts a higher LCZ temperature.

Wang et al. [7], studied the impact of the porosity permeable material on the saltiness dissemination under the consistent Lower Convective Zone (LCZ) temperature is tentatively by including permeable material. It tends to be derived that the impact of the permeable medium on salt dispersion will be likewise affected by the expansion of the temperature.

Assari et al. [8], studied the presentation of including stage change material (PCM) to little saltiness inclination sunpowered lake tentatively. Contrasting tentatively the sunpowered lake and without PCM, the most extreme normal temperature for the lake without PCM was higher than the lake with PCM.

Sarathkumar et al. [9], studied the execution of $\mathrm{Al}_{2} \mathrm{O}_{3}$ nanoparticles are included with PCM in the sun oriented lake. For the manufactured pilot sun-powered lake, the warmth balance investigation was controlled by performing heat move examination. It was discovered that the greatest measure of accessible helpful warmth vitality is $167 \mathrm{~W}$.

Agha [10], talked about the improvement of the size of the lake and the number of stages for three diverse stockpiling zone temperatures taking into accounts the enormous variety in the middle of summer and winter. He finished up the outcome is that prompting some dismissal of the warmth gathered throughout the mid-year will bring about a higher usage factor of the desalination plant and a decrease in the late spring/winter yield proportion.

Andrews and Akbarzadeh [11], explored with the point of opening the general energy proficiency of collecting sun based radiation, putting away heat, and conveying this heat to an application. It is reasoned that contrasted and the ordinary strategy for heat extraction the warmth extraction from the slope layer can expand the general vitality effectiveness of sun oriented lake conveying heat at a moderately high temperature by up to half, exclusively from the LCZ.

Appadurai and Velmurugan [12], researched the hypothetical execution and test investigation of a traditional sun-powered despite everything, balance type sun based despite everything, balance type sun based lake incorporated with blade type sun oriented still. The water assortment gain for the Fin type little sun-powered lake with customary sunlight based despite everything is $47 \%$, blade type single bowl sun based despite everything is $45.5 \%$ and balance type smaller than usual sun based lake coordinated with balance type single bowl sun-powered despite everything is half.

Berkani et al. [13], examined the warm conduct of three test little sun oriented lakes $(1 \mathrm{~m} \times 1 \mathrm{~m} \times 1 \mathrm{~m})$. One of the accompanying salts, to be specific Sodium Chloride, $\mathrm{Na}_{2} \mathrm{CO}_{3}$, and $\mathrm{CaCl}_{2}$ are contained in every one of the lakes. From the investigation, it is presumed that the lake with $\mathrm{CaCl}_{2}$ is thermally faster than the two different lakes without arriving at immersion.

Busquets et al. [14], considered the different saltiness inclinations that were performed dependent on the Stability Margin Number (SMN) standard, which is utilized to fulfill the dynamic steadiness measure. Because of convection in the LCZ and mass dissemination, there is an increasing speed of the NCZ. The thickness of the NCZ is significantly influenced as the $\mathrm{SMN}$ arrives at 1.5 was the resolution.

El-Sebaii et al. [15], played out the investigative model for the different components of the framework (the lake the still). $\mathrm{Up}$ to common estimations of $0.030 \mathrm{~m}$ and $0.015 \mathrm{~kg} / \mathrm{s}$, there is a lessening in the everyday profitability $\mathrm{P}_{\mathrm{d}}$ and effectiveness $\eta_{d}$ with expanding the thickness $d_{w}$ and mass stream rate $m$.

El-Sebaii et al. [16], researched the warm presence of a shallow sun-powered lake (SSP) under the open and shut cycle nonstop stream warming methods of warmth extraction were found hypothetically and tentatively. The day by day efficiencies for shut cycle mode is $59 \%$ and open cycle mode is $33 \%$. The STZ temperature can be increased by maintaining stable NCZ [17]. The multi-cell structure in the UCZ and the $\mathrm{LCZ}$, is generated by increasing of the aspect ratio further improves the fluid mixing in these two zones [18].

The temperature at the LCZ is higher in the unburied ponds [19]. The exergetic efficiencies are dependant on the turbidities of the zones [20].

Valderrama et al. [21], conducted an experiment using a salt-gradient solar pond and observed the maximum temperature at the $\mathrm{NCZ}$ and $10 \%$ of total solar radiation was quantified as heat loss. Goldoust et al. [22], the thermal characteristics of two-phased closed thermosyphon were 
experimentally studied. The maximum output is achieved for all the filling ratios at $60^{\circ}$.Alwan et al. [23], experimentally investigated the modified solar still and found that at low relative humidity when the solar irradiance is increased, the productivity of the solar still is in turn increased. La Rocca et al. [24], studied a solar pond for feeding a thermoelectric generator. The combination of SGSP and ORC gave higher efficiencies. Norozi et al. [25], studied the improvement of the solar radiation sing hourly sun-tracking solar still. The efficiency of solar irradiance is increased by $10-15 \%$.

A solar pond is a regular case of such a sort of warm gadget among different existed frameworks. Along these lines, it is critical to look into additional on the impact of this unique condition on solar pond execution. Thus, in the current examination, the temperature gradient, temperature conduct, and execution of permeable and non-permeable solar ponds explored. Two comparable solar ponds secured with meager plastic material with blended medium and regular in the lower convection zone (LCZ) were utilized in the LCZ.

As needs are, the impact of the permeable medium on the productivity of a sun-powered lake was concentrated tentatively. At last, an endeavor was made to get a hypothetical rule for evaluating the viability of utilizing blended mediums.

\section{EXPERIMENTAL SETUP}

\subsection{Design of experiment}

The mini-sized solar pond is cheap in cost, compared to the sized shallow ponds. In the current work, a simple and costefficient solar pond is designed.

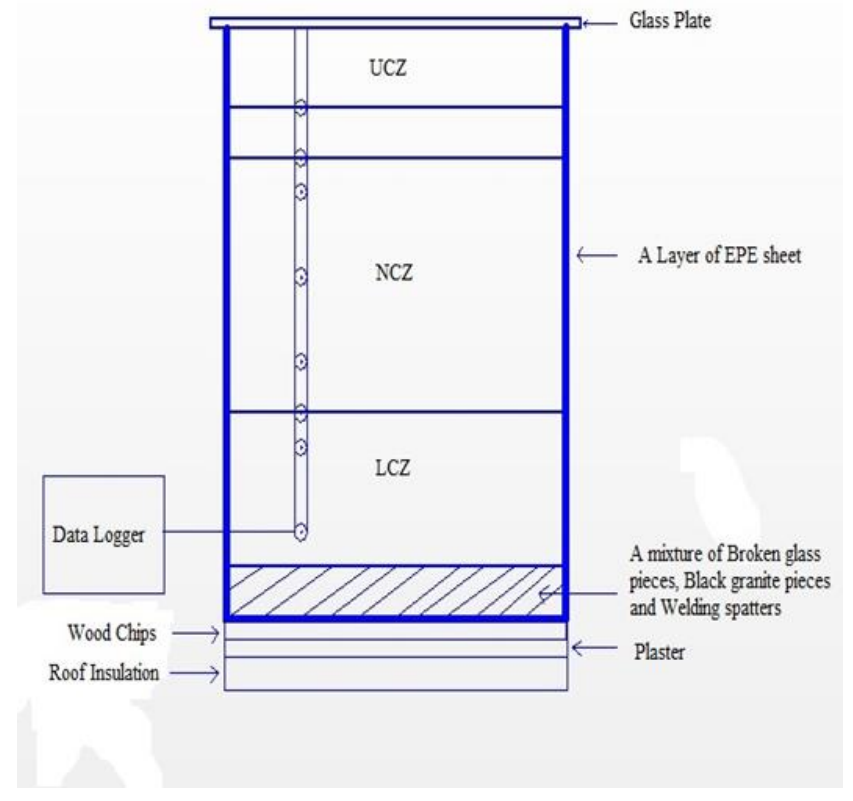

Figure 1. Schematic of the solar pond

Figure 1 represents the schematic of one of the solar ponds used. Two similar ponds of volume $0.02 \mathrm{~m}^{3}$, diameter $0.28 \mathrm{~m}$, and height $0.32 \mathrm{~m}$ are used in the experiment. The ponds are on the same ground level. The ponds used are made of stainless steel with a thickness of $3 \mathrm{~mm}$. The inner surface of the solar pond was painted black to absorb the incident solar radiation into the solar pond. To forestall the collection of residue on the top layer of water, the solar ponds are secured with glass plates (Figure 2a).

A thick layer of plaster is applied along with cotton cloth covering on the outer surfaces of both the ponds to prevent the escaping of the stored heat energy. Further, to forestall heat getting away from the outside of the ponds, a layer of EPE (Expanded Polyethylene) sheets with a thickness of $2 \mathrm{~cm}$ was used above the plaster layer for insulation (Figure 2b). Also, at the bottom surface of the solar ponds, a thick layer consisting of wood chips, plaster, and roof insulation materials are blended and applied on it. This is to prevent the heat from escaping through the bottom surface of the solar ponds.

Based on concentration of salt, the solar pond is classified into three individual zones to be specific, Lower Convective Zone (LCZ), Non-Convective Zone, (NCZ) and Upper Convective Zone (UCZ) of statures 12, 27 and $30 \mathrm{~cm}$ respectively. There are two solar ponds, one is the solar pond with a permeable medium and another is the non-permeable solar pond, sodium chloride salt is used in both the solar ponds (Figure 2c), where the saltiness is in the scope of $250 \mathrm{gm} / \mathrm{lit}$. of water. The base of the lake, the capacity zone, has the most elevated immersion pace of $0.3 \mathrm{~kg} / \mathrm{m}^{3}$, which is close to complete immersion. Welding splashes are utilized for putting away more warmth vitality in the blended medium. Stones are utilized for keeping the warmth from getting away from the welding spatter. Broken glass pieces are also put at the bottom of the solar pond which in turn aids in the prevention of conventional movement of the saltwater.

\subsection{Measurement method}

NI Compact DAQ (model NI 9213) data acquisition system is used to measure the temperatures at various zones of the solar pond as shown in Figure 2c. Temperatures are noted down in the ponds utilizing eight thermocouples at the statures of $5,10,12,15,20,25,27$ and $30 \mathrm{~cm}$ from base to top. $\mathrm{K}$ type and $J$ type thermocouples are utilized to quantify the temperatures in different zones. The thermocouples are associated with the information procurement framework in which the temperature esteems are recorded for each moment at a brief stretch and were utilized with an accuracy of $0.016^{\circ} \mathrm{C}$ $\pm 0.01 \%$. The density and specific gravity of saline water were estimated utilizing a pycnometer. LM35 model thermocouple was utilized with temperature ranges from zero to $125^{\circ} \mathrm{C}$ with $\pm 1^{\circ} \mathrm{C}$ precision. Furthermore, consequently, the readings are noted down at the different convective zones. The incident solar irradiance on the solar pond is measured using a pyranometer (model PMA1145).

\subsection{Experimental procedure}

The experiment was conducted at Government College of Engineering, Salem, in India. The solar ponds are fabricated and Sodium Chloride salt is mixed with water to the level of saturation. In the non-permeable solar pond the granite tones, broken glass pieces and, welding spatter were added and the top is covered with glass plate. Insulation is provided at the outer surface of the solar ponds. Temperature values were measured every day for a period of 30 days. Thermocouples were employed to continuously record the varying temperature values and also using the data logger the readings are consolidated and stored in the computer. The solar irradiance was also measured. 


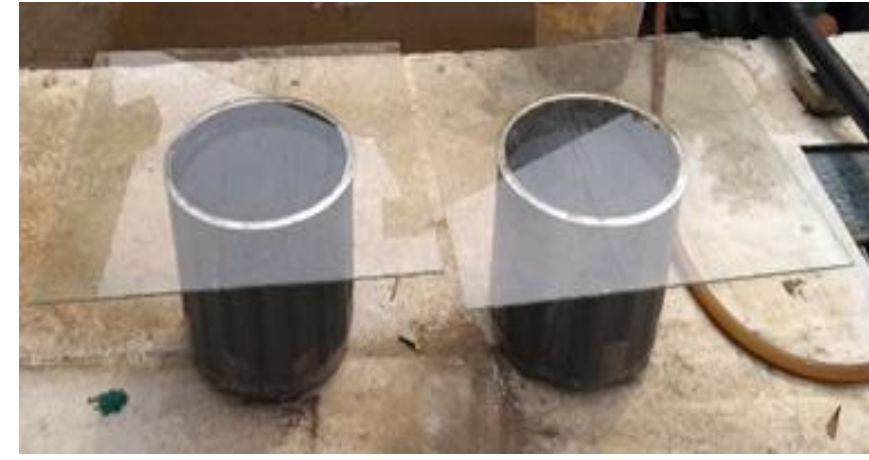

(a) Solar ponds covered with glass sheets

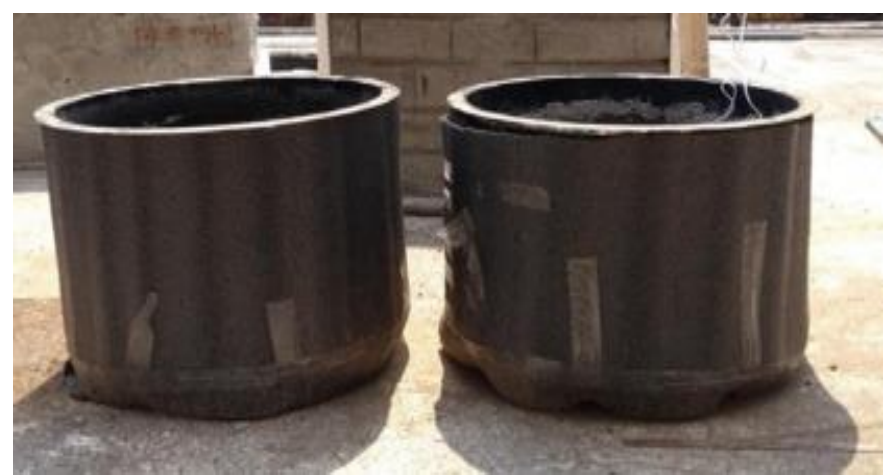

(b) Solar pond insulated

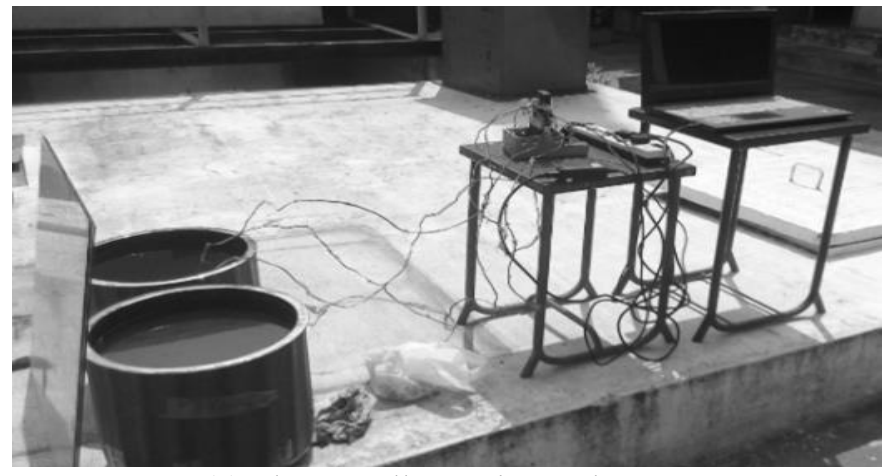

(c) The overall experimental setup

Figure 2. Experimental setup

\subsection{Uncertainty analysis}

The total uncertainty was measured for sensors and instrument accuracy using the following equation (Valderrama et al. [21]).

$$
\begin{gathered}
\delta_{\text {total }}=\sqrt{\left(\delta_{\text {instrument }}\right)^{2}+\left(\delta_{\text {sensor }}\right)^{2}} \\
\delta_{\text {instrument }}=0.0081^{\circ} \mathrm{C} \\
\delta_{\text {sensor }}=0.3632^{\circ} \mathrm{C} \\
\delta_{\text {total }}=0.363^{\circ} \mathrm{C}
\end{gathered}
$$

Thus, a repeatability test is conducted and the uncertainty in the measurement was estimated.

\section{MODELING AND OPTIMIZATION}

The total heat storage in the mixed medium solar pond is given as [1].

$$
\mathrm{E}_{\mathrm{MMSP}}=\mathrm{E}_{\mathrm{br}}+\mathrm{E}_{\mathrm{gp}}+\mathrm{E}_{\mathrm{ws}}
$$

Here $\mathrm{E}_{\mathrm{br}}, \mathrm{E}_{\mathrm{gp}}, \mathrm{E}_{\mathrm{ws}}$ are heat storage $(\mathrm{kJ})$ in the brine, granite pieces, and welding spatter.

$$
\mathrm{E}_{\mathrm{MMSP}}=\mathrm{C}_{\mathrm{br}} \mathrm{m}_{\mathrm{br}} \Delta \mathrm{T}+\mathrm{C}_{\mathrm{gp}} \mathrm{m}_{\mathrm{gp}} \Delta \mathrm{T}+\mathrm{C}_{\mathrm{ws}} \mathrm{m}_{\mathrm{ws}} \Delta \mathrm{T}
$$

$\mathrm{C}_{\mathrm{br}}, \mathrm{C}_{\mathrm{gp}}, \mathrm{C}_{\mathrm{ws}}$ are heat capacity $\left(\mathrm{kJ} / \mathrm{kg}^{\circ} \mathrm{C}\right)$ in the brine, granite pieces and welding spatter, respectively and $\mathrm{m}_{\mathrm{br}}, \mathrm{m}_{\mathrm{gp}}, \mathrm{m}_{\mathrm{ws}}$ are mass $(\mathrm{kg})$ in the brine, granite pieces, and welding spatter, respectively, and $\Delta \mathrm{T}$ is the temperature difference $\left({ }^{\circ} \mathrm{C}\right)$.

$$
\begin{gathered}
\mathrm{E}_{\mathrm{MMGP}}=\mathrm{V} \Delta \mathrm{T}\left[(1-\mathrm{x}-\mathrm{y}) \mathrm{C}_{\mathrm{br}} \rho_{\mathrm{br}}+\mathrm{xC}_{\mathrm{pb}} \rho_{\mathrm{pb}}\right. \\
\left.\mathrm{I}+\mathrm{yC}_{\mathrm{bb}} \rho_{\mathrm{bb}}\right] \\
E_{M M S P}=V \Delta T(\rho C)_{b r}\left[(1-x-y)+x \frac{C_{p b}}{C_{b r}} \frac{\rho_{p b}}{\rho_{b r}}\right. \\
\left.+y \frac{C_{b b}}{C_{b r}} \frac{\rho_{b b}}{\rho_{b r}}\right] \\
\beta_{\mathrm{elk}}=\left[\left(1-\frac{\mathrm{C}_{\mathrm{pb}}}{\mathrm{C}_{\mathrm{br}}} \frac{\rho_{\mathrm{pb}}}{\rho_{\mathrm{br}}}\right)+\mathrm{a}\left(1-\frac{\mathrm{C}_{\mathrm{bb}}}{\mathrm{C}_{\mathrm{br}}} \frac{\rho_{\mathrm{bb}}}{\rho_{\mathrm{br}}}\right)\right]
\end{gathered}
$$

Here, $\beta_{\text {elk }}$ is a criterion parameter to indicate which permeable material is optimal for saving energy and to use economically. Significantly, $\beta_{\text {elk }}$ is used to call this criterion. Even though more energy will be stored by increasing the depth of LCZ, the depth of LCZ in MMSP is restricted from the economical point of view caused by the cost of salt, etc. Hence, it can be adequate to utilize low-cost permeable medium with $\beta_{\text {elk }} \leq 0$.

\section{RESULTS AND DISCUSSIONS}

The permeable and non-permeable solar ponds are taken for the experiment because in the non-permeable solar pond the salt concentration will be even throughout the solar pond. In the permeable solar pond, the materials such as granite pieces, broken glass pieces and welding spatter are used to store extra heat in the bottom layer of the solar pond where the salt concentration is higher.

The experiment was conducted in a place which is located in the tropical region of the Earth. It will be sufficient to experiment for a period of 30 days and the results gave the exact value as expected.

Figure 3 compares typical LCZ temperature contrasts of both suns-oriented ponds to the encompassing temperature. After 30 days of observation, the average temperature at the $\mathrm{LCZ}$ in the ponds with the non-porous and porous pond of $\mathrm{NaCl}$ solution was obtained as $42.3^{\circ} \mathrm{C}$ and $40.6^{\circ} \mathrm{C}$ respectively. The temperature of the permeable solar pond increases to $39^{\circ} \mathrm{C}$ on day 4 and decreases to $25^{\circ} \mathrm{C}$ on day 5 due to the temporarily varying weather conditions (raining). After day 25 the temperature in the permeable solar ponds crosses $39^{\circ} \mathrm{C}$ and after which there is an increment in the value. Looks at ordinary LCZ temperature contrasts of both suns-based lakes to the surrounding temperature. Experimental results in the first three days indicate that the storage temperature rises in an equal manner in both the solar ponds, in further days the temperature values for the permeable medium solar pond increases at a higher range compared to the non-permeable medium solar pond. 


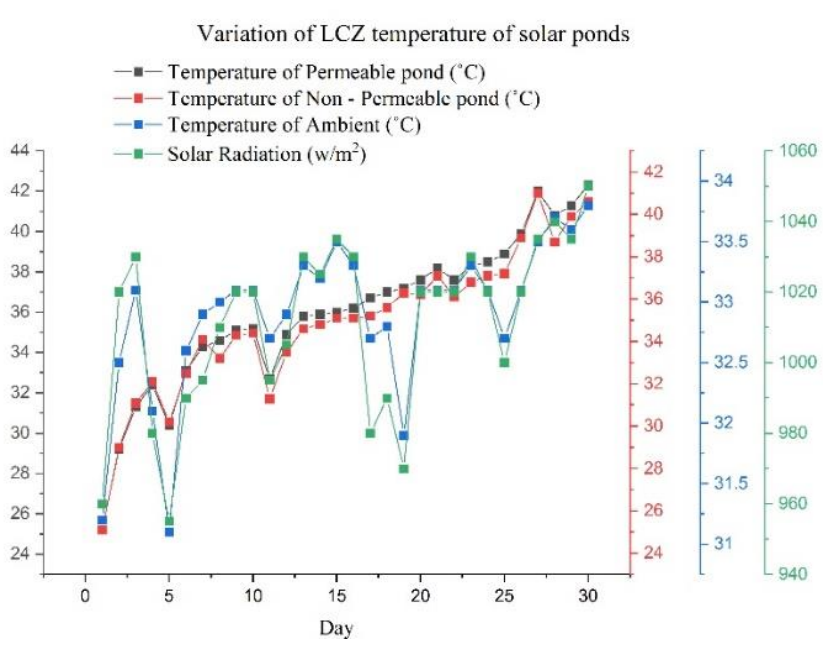

Figure 3. Variation of LCZ temperature of solar ponds

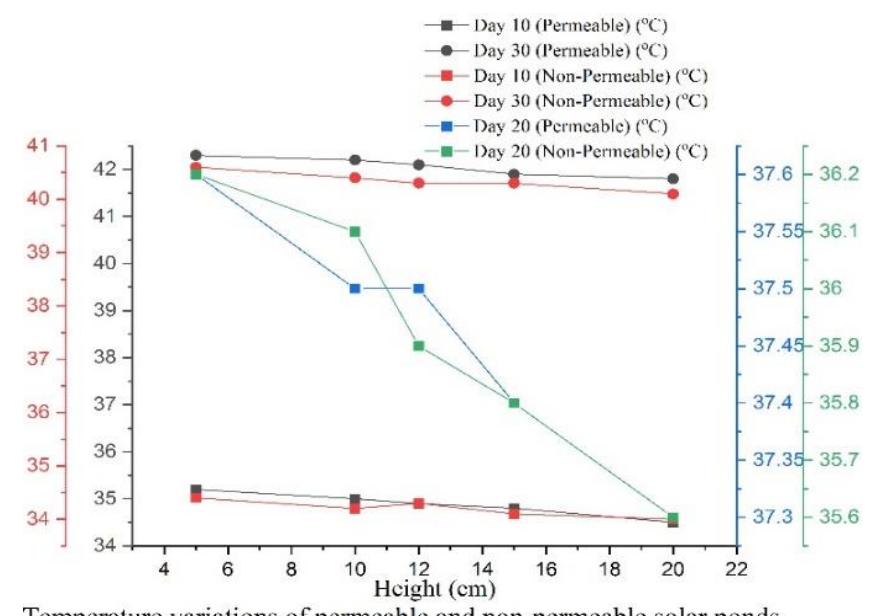

Temperature variations of permeable and non-permeable solar ponds

Figure 4. Temperature variations of permeable and nonpermeable solar ponds

Figure 4 delineates the temperature inclinations of both sunlight-based lakes. It very well may be seen from the Figure that the floor temperature of blended medium and customary LCZ arrived at $42.3^{\circ} \mathrm{C}$ and $40.6^{\circ} \mathrm{C}$ on the $30^{\text {th }}$ day, individually. The greatest temperature saw in the penetrable lake was not on the floor of the lake yet somewhat higher than the base of the lake. For example, on the $20^{\text {th }}$ day, the temperature at the floor of the porous lake arrived at $36.2^{\circ} \mathrm{C}$ while the most extreme temperature of the lake was $37.6^{\circ} \mathrm{C}$. Consequently, the most extreme temperature is $3.87 \%$ higher than the floor temperature. Additionally, the temperature contrast among $\mathrm{LCZ}$ and $\mathrm{UCZ}$ in day 30 was equivalent to $1.7^{\circ} \mathrm{C}$, because utilizing coating plastic spread caused an expansion in UCZ temperature because of square warmth from getting away.

Figure 5 shows the thickness variety in sun-powered lakes. As time advances, the salt moves upward because of the regular dissemination. This rolls out certain improvements in the thickness and saltiness of the water. Further, it shows the saltiness of the lake floor diminishes in time and the thickness of the blended medium is more than the non-penetrable sunpowered lake inconclusive days. For instance, in this examination, for LCZ the saltiness advancement in the Permeable medium pond is $14 \%$ lower than that of the nonpermeable solar pond for 15 days and $33 \%$ for 30 days.

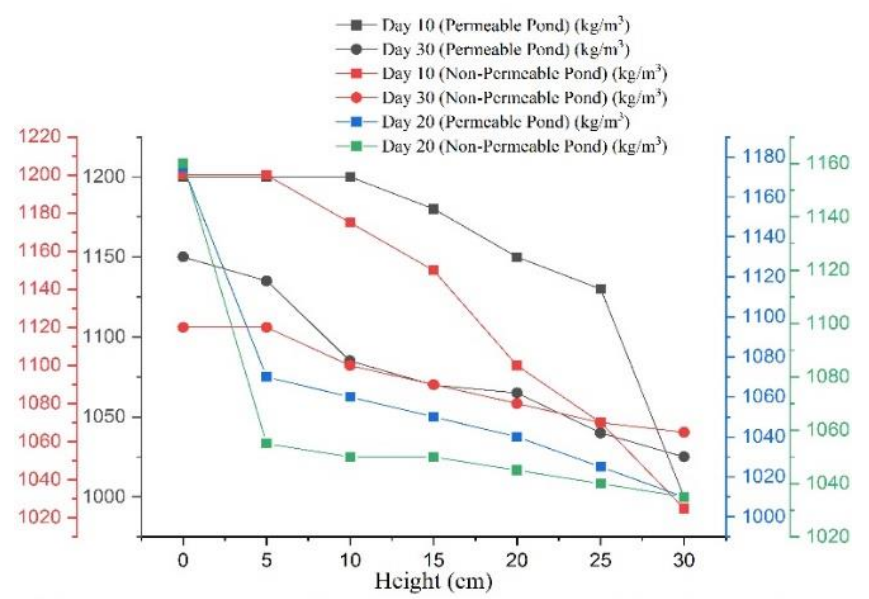

Gradient density variation of permeable and non-permeable solar ponds

Figure 5. Gradient density variation of permeable and nonpermeable solar ponds

Over a long period of use of the solar pond, crystals will be formed on the inner surface of the solar pond. Also, the sedimentary rate of the solar pond will be increased over a long period of usage. So, this can be prevented by stirring the solar pond after extracting the heat from it.

Consequently, in this examination, broken glass pieces were added to the LCZ as a layer over the welding splash and dark rock pieces to make up for the warmth stockpiling limit. Thus, the most extreme temperature is $4.18 \%$ higher than the floor temperature. Additionally, the temperature distinction among $\mathrm{LCZ}$ and UCZ in day 15 was equivalent to $30^{\circ} \mathrm{C}$ because utilizing a glass plate spread caused an expansion in UCZ temperature because of square warmth from getting away. In this manner, at last, it is found from the readings acquired that penetrable medium sun-oriented lake stores more measure of warmth vitality in Lower Convective Zone than that of the non-porous sun based lake.

\section{CONCLUSION}

There is a plentiful measure of solar radiation in the southern district of India. So, it is right to store solar energy in this area. Also, it is of less windy area, so it is a much-suited place to perform this experiment. The southern region of India is located in the tropical region of the Earth were a large amount of solar radiation. In this study, two comparable solar ponds with a similar cross-segment and amount of water with the permeable medium in one solar pond and another nonpermeable solar pond are explored tentatively. The conveyance of temperature, temperature contrast, and salt gradient, on the activity of changing salt thickness solar ponds, is incorporated for a time of 30 days. To indicate the effect of the permeable medium in storing the heat energy, dimensionless numbers are used. A criterion parameter was given to for showing which permeable material is appropriate for saving energy. From the literature survey, it is known that more amount of energy will be stored by increasing the depth of LCZ. Perfect suitable permeable material is chosen after laboratory testing was conducted. Also, from the economic point of view the permeable materials were chosen.

More amount of energy can be stored with increased depth in the LCZ, but considering the economic point of view that might be caused due to the cost of salt the depth of the LCZ is 
limited.

Hence it is better to use the cheaper mixed medium solar pond. The temperatures at the lower convective zones are $42.30^{\circ} \mathrm{C}$ and $40.60^{\circ} \mathrm{C}$ in the solar ponds with permeable medium and non- permeable solar pond respectively.

Thus, the temperature obtained from the permeable medium solar pond is higher than the non-permeable solar pond. Therefore, the solar pond with a permeable medium indicated an increase of $4.18 \%$ in temperature.

The results obtained in this experiment were similar to the previous work did by other researchers [1]. The mixed medium solar pond indicated an increase of $5.6 \%$ in temperature due to a very large volume of the solar pond it shows a higher increase in temperature.

Due to the usage of more amount of thermal insulation materials, the variation of temperature $\left(1.7^{\circ} \mathrm{C}\right)$ in the solar ponds indicated that these variations are less compared to the ambient temperature values.

It is better to use a solar pond $\beta_{\text {elk }} \leq 0$ to reduce the economic cost.

Also, it was found that the dust accumulation over the glass plate on the solar pond has some negative effects on storing thermal energy. The contrast between the measures of heat transfer is $4.54 \mathrm{~kJ}$.

Henceforth the solar ponds with the permeable medium are favored the best to use.

\section{REFERENCES}

[1] Assari, M.R., Tabrizi, H.B., Parvar, M., Nejad, A.K., Beik, A.J.G. (2017). Experiment and optimization of mixed medium effect on small-scale salt gradient solar pond. Solar Energy, 151: 102-109. https://doi.org/10.1016/j.solener.2017.04.042

[2] Hill, A.A., Carr, M. (2013). Stabilising solar ponds by utilising porous materials. Advances in Water Resources, 60: 1-6. https://doi.org/10.1016/j.advwatres.2013.07.005

[3] Shi, Y., Yin, F., Shi, L., Wence, S., Li, N., Liu, H. (2011). Effects of porous media on thermal and salt diffusion of solar pond. Applied Energy, 88(7): 2445-2453. https://doi.org/10.1016/j.apenergy.2011.01.033

[4] Silva, G., Almanza, R. (2009). Use of clays as liners in solar ponds, Solar Energy, 83(6): 905-919. https://doi.org/10.1016/j.solener.2008.12.008

[5] Velmurugan, V., Mandlin, J., Stalin, B., Srithar, K. (2009). Augmentation of saline streams in solar stills integrating with a mini solar pond, Desalination, 249(1): 143-149. https://doi.org/10.1016/j.desal.2009.06.016

[6] Wang, H., Zou, J., Cortina, J.L., Kizito, J. (2014). Experimental and theoretical study on temperature distribution of adding coal cinder to bottom of salt gradient solar pond. Solar Energy, 110: 756-767. https://doi.org/10.1016/j.solener.2014.10.018

[7] Wang, H., Yu, X., Shen, F., Zhang, L. (2015). A laboratory experimental study on effect of porous medium on salt diffusion of salt gradient solar pond. Solar Energy, 122: 630-639. https://doi.org/10.1016/j.solener.2015.09.005

[8] Assari, M.R., Tabrizi, H.B., Beik, A.J.G. (2015). Experimental studies on the effect of using phase change material in salinity-gradient solar pond. Solar Energy, 122:

204-214
[9] Sarathkumar, P., Sivaram, A.R., Rajavel, R., Kumar, R. P., Krishnakumar, S.K. (2017). Experimental investigations on the performance of a solar pond by using encapsulated PCM with nanoparticles. Materials Today: Proceedings, 4(2): 2314-2322. https://doi.org/10.1016/j.matpr.2017.02.080

[10] Agha, K.R. (2009). The thermal characteristics and economic analysis of a solar pond coupled low temperature multi stage desalination plant. Solar Energy, 83(4): 501-510. https://doi.org/10.1016/j.solener.2008.09.008

[11] Andrews, J., Akbarzadeh, A. (2005). Enhancing the thermal efficiency of solar ponds by extracting heat from the gradient layer. Solar Energy, 78(6): 704-716. https://doi.org/10.1016/j.solener.2004.09.012

[12] Appadurai, M., Velmurugan, V. (2015). Performance analysis of fin type solar still integrated with fin type mini solar pond. Sustainable Energy Technologies and Assessments, 9:

$30-36$. https://doi.org/10.1016/j.seta.2014.11.001

[13] Berkani, M., Sissaoui, H., Abdelli, A., Kermiche, M., Barker-Read, G. (2015). Comparison of three solar ponds with different salts through bi-dimensional modeling. Solar Energy, 116: 56-68. https://doi.org/10.1016/j.solener.2015.03.024

[14] Busquets, E., Kumar, V., Motta, J., Chacon, R., Lu, H. (2012). Thermal analysis and measurement of a solar pond prototype to study the non-convective zone salt gradient stability. Solar Energy, 86(5): 1366-1377. https://doi.org/10.1016/j.solener.2012.01.029

[15] El-Sebaii, A.A., Aboul-Enein, S., Ramadan, M.R.I., Khallaf, A.M. (2011). Thermal performance of an active single basin solar still (ASBS) coupled to shallow solar pond (SSP). Desalination, 280(1-3): 183-190. https://doi.org/10.1016/j.desal.2011.07.004

[16] El-Sebaii, A.A., Aboul-Enein, S., Ramadan, M.R.I., Khallaf, A.M. (2013). Thermal performance of shallow solar pond under open and closed cycle modes of heat extraction. Solar Energy, 95: 30-41. https://doi.org/10.1016/j.solener.2013.05.026

[17] Husain, M., Sharma, G., Samdarshi, S.K. (2012). Innovative design of non-convective zone of salt gradient solar pond for optimum thermal performance and stability. Applied Energy, 93: 357-363. https://doi.org/10.1016/j.apenergy.2011.12.042

[18] Boudhiaf, R., Baccar, M. (2014). Transient hydrodynamic, heat and mass transfer in a salinity gradient solar pond: a numerical study. Energy Conversion and Management, 79: 568-580. https://doi.org/10.1016/j.enconman.2013.12.068

[19] Sayer, A.H., Al-Hussaini, H., Campbell, A.N. (2016). New theoretical modelling of heat transfer in solar ponds. Solar Energy, 125: 207-218. https://doi.org/10.1016/j.solener.2015.12.015

[20] Atiz, A., Bozkurt, I., Karakilcik, M., Dincer, I. (2014). Investigation of turbidity effect on exergetic performance of solar ponds. Energy Conversion and Management, 87: 351-358. https://doi.org/10.1016/j.enconman.2014.07.016

[21] Valderrama, C., Gibert, O., Arcal, J., Solano, P., Akbarzadeh, A., Larrotcha, E., Cortina, J.L. (2011). Solar energy storage by salinity gradient solar pond: pilot plant construction and gradient control. Desalination, 279(1-3): 
https://doi.org/10.1016/j.desal.2011.06.035

[22] Goldoust, A., Emami, M.R.S., Ranjbar, A.A. (2019). Experimental investigation of the evaporator section tilted angle and filling ratio on the thermal charateristics of a two-phase closed thermosyphon. International Journal of Heat and Technology, 37(2): 569-574. https://doi.org/10.18280/ijht.370226

[23] Alwan, N.T., Shcheklein, S.E., Ali, O.M. (2020). Experimental investigation of modified solar still productivity under variable climatic conditions. Case Studies in Thermal Engineering, 19: 100614. https://doi.org/10.1016/j.csite.2020.100614

[24] La Rocca, V., Morale, M., Peri, G., Scaccianoce, G. (2017). A solar pond for feeding a thermoelectric generator or an organic Rankine cycle system. International Journal of Heat and Technology, 35(1): S435-S441. https://doi.org/10.18280/ijht.35Sp0159

[25] Norozi, M. (2017). Experimental investigation of improving received radiation by an hourly sun tracking on a weir-type cascade solar still. International Journal of Heat and Technology, 35(4): 737-746. https://doi.org/10.18280/ijht.350407

\section{NOMENCLATURE}

$\begin{array}{ll}\mathrm{Cp} & \text { heat capacity }\left(\mathrm{kJ} / \mathrm{kg}{ }^{\circ} \mathrm{C}\right) \\ \mathrm{E} & \text { storage heat of energy }(\mathrm{kJ}) \\ \mathrm{e} & \text { energy per volume }\left(\mathrm{kJ} / \mathrm{m}^{3}\right) \\ \mathrm{m} & \text { mass }(\mathrm{kg}) \\ \mathrm{V} & \text { volume }\left(\mathrm{m}^{3}\right)\end{array}$

\section{Greek symbols}

$\Delta \mathrm{T}$
$\rho$
$\beta_{\text {elk }}$

$\delta_{\text {instrument }}$
$\delta_{\text {sensor }}$
$\delta_{\text {total }}$

temperature difference $\left({ }^{\circ} \mathrm{C}\right)$ density $\left(\mathrm{kg} / \mathrm{m}^{3}\right)$

criterion parameter for indicating which porous material is suitable for energysaving or economically feasible to use instrument accuracy sensor accuracy total uncertainty

\section{Subscripts}

$\begin{array}{ll}\text { br } & \text { brine } \\ \text { gp } & \text { granites pieces } \\ \text { ws } & \text { welding spatter }\end{array}$

